\title{
Obsessive compulsive disorder and basal ganglia dysfunction ${ }^{1,2}$
}

There is increasing evidence that selective basal ganglia dysfunction underlies obsessive-compulsive disorder (OCD). Recent neuroanatomical, neuropharmacological, and behavioural studies indicate a complex perceptual and cognitive role for the basal ganglia in addition to their more well-accepted motor functions. In addition, obsessive-compulsive symptoms in certain syndromes and in individual cases with basal ganglia disease, response to psychosurgery, and new antiobsessional drugs and recent brain-imaging studies all support such a model. OCD may represent the inappropriate triggering of genetically stored and learned behaviours by the striatum as the primary cause of OCD.

\section{EVIDENCE FOR THE HYPOTHESIS}

\section{Syndromes linked to the basal ganglia}

\section{Tourette's syndrome and tics}

In his original 1885 description of a syndrome associated with the basal ganglia that today bears his name, Gilles de la Tourette reported a relationship between recurrent motor and phonic tics and obsessive-compulsive behaviour. He described a patient who suffered from tics and vocalizations and from tormenting, obsessive thoughts. Systematic studies have shown a link between Tourette's syndrome and obsessive-compulsive disorder (OCD) (Pauls et al. 1986), and 15-18\% of Tourette's patients are described as having at least some obsessive-compulsive symptoms, in excess of the $2 \%$ lifetime prevalence compulsive disorder found in the US population (Karno et al. 1988). Conversely, tics occur in childhood OCD far more frequently than would be expected by chance (Swedo et al. in the press).

There is almost a century of recorded associations between simple motor tics and OCD. Osler, in his 1894 monograph On Chorea and Choreiform Affections, for example, described a girl with 'tic of muscles of the face and neck; fixed ideas; arithmomania'.

\section{Postencephalitic Parkinson's disease}

Neurologically based OCD was described by Constantin von Economo, whose monograph of 1917 (translated to English in 1931) contains elegant clinical descriptions of postencephalitic disorders. He reported that this infectious, neurotoxic disease involved the basal ganglia and was associated with a sense of compulsion reminiscent of $O C D$, in addition to motor changes. In discussing the psychological changes in these patients, von Economo argued against a role of the cerebral cortex in the generation of these uncontrollable movements and instead focused on subcortical centres, presumably including the basal ganglia. Von Economo also noted a whole range of peculiar tics associated with these compulsions including blepharospasms, mimetic tics of clucking or hissing, torticollis, and tics of the upper and lower extremities as well as fits of yelling and yawning. Von Economo concluded that 'motor disturbances of encephalitics were reminiscent of compulsive movements and compulsive actions, with frequently ensuing utterances of speech and trends of thought of a compulsive character'.

\footnotetext{
' Adapted from Wise, S. \& Rapoport, J. (1989) Obsessive compulsive disorder is it basal ganglia dysfunction? In Obsessive Compulsive Disorder in Children and Adolescents (ed. J. Rapoport), pp. 327-346. American Psychiatric Press: Washington, DC.

Address for correspondence: Dr Judith L. Rapoport, Child Psychiatry Branch, National Institute of Mental Health, Bethesda, MD 20892, USA.
} 


\section{Sydenham's chorea}

Sydenham's chorea, a disorder of children and adolescents, is characterized by sudden, aimless, irregular movements of the extremities that are frequently associated with emotional instability and muscle weakness. In children, the disorder occurs after rheumatic heart disease, as part of the complex of rheumatic fever. Postmortem studies of Sydenham's chorea have reported that perivascular cellular infiltration and neural degeneration are most pronounced in the striatum (Greenfield \& Wolfsohn, 1922), and contained specific antibodies to caudate and putamen nucleus neurons (Husby et al. 1976). Thus, this disorder is of particular interest since it occurs exclusively in young people, may involve an autoimmune disease of the basal ganglia, and has been linked with OCD (Grimshaw, 1964; Freeman, 1965).

In an ongoing survey of obsessive symptoms in children with Sydenham's chorea (Swedo et al. 1989), three of the 23 examined to date and none of the 14 rheumatic fever controls showed a clinical level of obsessive-compulsive symptoms. Subclinical automatic, compulsive, and stereotyped behaviours and thoughts were also more frequent in the chorea patients.

\section{Other presumed basal ganglia disorders}

Several cases have been reported in which discrete lesions of the basal ganglia produced psychological changes that resemble obsessional illness. (Laplane et al. 1984, 1989; Denckla, 1989; Tonkonogy \& Barreira, 1989).

\section{Brain imaging studies}

More direct data about a role of the basal ganglia in OCD were found by Luxenberg et al. (1988), who demonstrated a smaller volume of the caudate nuclei bilaterally in ten obsessive-compulsive male patients $(P=0.001)$; their lenticular nuclei and thalami did not differ from those of the control subjects.

Baxter et al. (1987), using positron emission tomography (PET), found higher metabolic rates bilaterally in the caudate nuclei and the lateral orbitofrontal cortices of obsessive-compulsive patients compared to depressed or normal control subjects.

\section{Psychosurgery}

OCD is one of the few psychiatric disorders for which psychosurgery may be indicated (Kettle \& Marks, 1986). The best documented studies are those examining anterior capsulotomy or cingulectomy, currently the preferred operations; all of these interrupt frontal lobe striatal connection. Further, Hassler (1982) found that stereotaxic lesions in the mediodorsal and anterior nuclei of the thalamus, and their projection systems to the cortex, may diminish the symptoms of both Tourette's syndrome and OCD.

\section{Neuropharmacology}

Clomipramine, fluoxetine and fluvoxamine have relatively selective action on the serotonergic system and have selective benefit in ameliorating obsessive-compulsive symptoms. This striking clinical phenomenon has led to a 'serotonergic hypothesis' of OCD (Insel et al. 1985; Flament et al. 1987; Zohar et al. 1987). This is compatible with our basal ganglia hypothesis as recent studies (Steinbusch, 1981; Stuart et al. 1986) have indicated higher concentrations of serotonin (5HT-2) receptors and serotonin itself in the basal ganglia than has previously been recognized. In rats, the concentration of serotonin is particularly high in the nucleus accumbens and ventral striatum, but it is present throughout the striatum, including the caudate and putamen (Steinbusch, 1981; Pazos \& Palacius, 1985; Pazos et al. 1985; Stuart et al. 1986). 


\section{HYPOTHESIS: BASAL GANGLIA DYSFUNCTION AS A CAUSE OF OBSESSIVE-COMPULSIVE DISORDER}

New information about the basal ganglia and their interactions with the cerebral cortex and other subcortical structures, most notably the thalamus (Alexander et al. 1986), make us see interconnections among these structures which can be viewed as 'loops', i.e. 'closed' polysynaptic circuits in which the cortex sends efferents to the basal ganglia. It seems likely that some of the parallel loops may function primarily in a motor function, whereas others mediate perceptual and cognitive functions.

Central to the hypothesis is the notion that the basal ganglia may be a repository of innate motor programmes (MacLean 1978; Greenberg et al. 1979; Murphy et al. 1981) and the other is that the basal ganglia function, in part, acts as a gating mechanism for sensory input (Schneider 1984; Caligiuri \& Abbs, 1987). The model poses as an innate releasing mechanism in the basal ganglia: a detection mechanism for recognizing specific aspects of stimuli (key or sign stimuli) and a releasing mechanism for the species-typical behavioural response (analogous to a fixed action pattern), although displacement behaviours also must be considered (Swedo et al. 1989 b). This model is presented in detail elsewhere (Wise \& Rapoport 1989). The circuit hypothesized to go awry is the 'orbitofrontal loop' described by Alexander et al. (1986) and includes the orbitofrontal cortex, the caudate nucleus (striatum), the globus pallidus and the substantia nigra pars reticulata (pallidum), and the ventroanterior and mediodorsal thalamic nuclei. In this model, a sensory input, e.g. the recognition of dirtiness, is received by an innately programmed striatal cell group, which discharges inhibiting an appropriate pallidal cell. There is a converging circuit originating from the anterior cingulate cortex relaying through the same (hypothetical) pallidal cell group which provides a signal whenever an act is performed because of an exclusively internal motivation. (Some experimental support has been found for such a role of the cingulate cortex (Brooks, 1986).) A similar argument can be made for a cognitive function of the basal ganglia in relation to obsessive thoughts. Further, if the output of another circuit were blocked or dysfunctional, build-up of basal ganglia activity, with its extensive intrinsic collateral interactions, might cause the 'sparking over' to a displacement activity (Lorenz, 1981).

\section{The model and the phenomenology of obsessive-compulsive disorder}

Several aspects of the data on OCD are accounted for by this model, and it makes some testable predictions. First, the effects of psychosurgery are explained, since destruction of the anterior cingulate cortex, its thalamic input, and its efferent pathways to the caudate nucleus or the caudate itself would eliminate the excitatory drive to the 'internal motivation detector'.

The symptoms most common in OCD, washing and concern with contamination and dirt are seen as evolutionarily meaningful behaviours inappropriately released in this disorder. Other behaviours, not ordinarily associated with OCD, such as trichotillomania, severe nail biting and face picking respond selectively to clomipramine but not desmethylimipramine (Swedo et al. $1989 \mathrm{c}$ ), and are viewed as 'grooming behaviours run wild'. Further support to our ethological model is our recent finding that dogs with acral lick dermatitis, a condition in which excessive licking produces leg lesions, also improve selectively on clomipramine but not on desmethylimipramine (Goldberg \& Rapoport, 1990).

\section{COMMENT}

Clinically some information appears to be inconsistent with a 'basal ganglia hypothesis' of OCD. Other neurological disorders of the basal ganglia, such as Huntington's disease and idiopathic Parkinsonism, are associated with depression and psychotic symptoms but increased rates of OCD have not yet been described for these conditions. In postencephalitic Parkinsonian patients, as we have noted, lesions outside the basal ganglia may be related to the obsessions. Moreover, a variety of brain insults, such as head trauma, diabetes, and birth injury, appear to be associated with OCD (Kettle \& Marks, 1986). It is possible that when these generalized disorders are associated with 
OCD there is also basal ganglia damage, but we know of no evidence of such damage. However, differential sensitivity of the basal ganglia to anoxia and to some neurotoxins is well established. (Langston et al. 1983; Insel et al. 1985).

Newer imaging techniques and/or autopsy data may eventually resolve these issues in favour of the 'basal ganglia hypothesis', but for now they must be recognized as serious objections.

The present hypothesis also fails to account for the behavioural specificity (for one or two thoughts or actions at a time), and the efficacy of behaviour therapy in OCD. Specific symptom pattern is in part related to age of onset (Swedo et al. $1989 \mathrm{c}$ ). The efficacy of behavioural treatment at least in selected cases, does not prove a dysfunctional reinforcement history. Conversely, innate behaviours may be altered through conditioning. In balance, however, the basal ganglia dysfunction model for OCD provides the most useful framework to date for viewing both past and the wealth of new research information on this fascinating psychiatric disease.

JUDITH L. RAPOPORT

\section{REFERENCES}

Alexander, G., DeLong, M. \& Strick, P. (1986). Parallel organization of functionally segregated circuits linking basal ganglia and cortex. Annual Review's of Neuroscience 9, 357-381.

Baxter, L. R. Jr., Phelps, M. E., Mazziotta, J. C., Guze, B. H., Schwartz, J. M. \& Selin, C. E. (1987). Local cerebral glucose metabolic rates in obsessive-compulsive disorder: a comparison with rates in unipolar depression and in normal controls. Archives of General Psychialry 44, 211-218.

Brooks, V. (1986). Does the limbic system assist motor learning? A limbic comparator hypothesis. Brain Behaviour and Evolution 29, 29-53.

Caligiuri, M. P. \& Abbs, J. H. (1987). Response properties of the perioral reflex in Parkinson's disease. Experimental Neurology 98 , 563-572.

Denckla, M. B. (1989). The neurological examination. In Obsessive-Compulsive Disorder in Children and Adolescents (ed. J. L. Rapoport), pp. 107-118. American Psychiatric Press: Washington, DC.

Flament, M., Rapoport, J. L., Murphy, D., Berg, C. T. \& Lake, R. (1987). Biochemical changes during clomipramine treatment of childhood obsessive compulsive disorder. Archives of General Psychiatry 44, 219-225.

Freeman, J., Aron, A., Collard, J. \& MacKay, M. (1965). The emotional correlates of Sydenham's chorea. Pediatrics 35, 42-49.

Gilles de la Tourette; G. (1885). Études sure une affection nerveuse caracterisée par de l'incoordination motrice accompagnée d'echolalie et de copraolalie. Archives of Neurology (Paris) 9, (1942), 158-200.

Goldberg, E. \& Rapoport, J. (1990). Canine acral lick dermatitis: response to the anti-obsessional drug clomipramine. Journal of American Animal Hospital Association (in the press).

Greenberg, N., MacLean, P. D. \& Ferguson, J. L. (1979). Role of the paleostriatum in species-typical display behavior of the lizard. Brain Research 172, 229-241.

Greenfield, G. \& Wolfsohn, J. M. (1922). The pathology of Sydenham's Chorea. Lancet pp. 603-607.

Grimshaw, L. (1964). Obsessional disorder and neurological illness Journal of Neurology, Neurosurgery and Psychiatry 27, 229-231.

Hassler, R. (1982). The role of the thalamus and striatum in the causation of tics and compulsive vocalization. Paper presented at the First International Tourette Syndrome Symposium, New York. 1981.

Husby, G., van de Rijn, I., Zabriskie, J. B., Abdin, Z. H. \& William, R. C. (1976). Antibodies reacting with cytoplasm of subthalamic and caudate nuclei neurons in chorea and acute rheumatic fever. Journal of Experimental Medicine 144, 1094-1110.

Karno, M., Golding, J., Sorensun, S. \& Burnam, A. (1988). The epidemiology of obsessive compulsive disorder in five US communities. Archives of General Psychiatry 45, 1094-1099.
Kettle, P. \& Marks, I. (1986). Neurological factors in obsessive compulsive disorder. British Journal of Psychiatry 149, 315-319.

Langston, J., Ballard, P., Tetrud, J. \& Irwin, 1. (1983). Chronic parkinsonism in humans due to a product of meperidine-analog synthesis. Science 219, 979-980.

Laplane, D., Baulac, M., Widlocher, D. \& Dubois, B. (1984). Pure psychic akinesia with bilateral lesions of basal ganglia. Journal of Neurology, Neurosurgery and Psychiatry 47, 377-385.

Laplane, D., Levasseur, M., Pilloni, B., Dubois, B., Baulac, M., Mazoyer, B., Tranbinh, S., Settle, G., Danze, F. \& Baron, J. (1989). Obsessive compulsive and other behavioural changes with bilateral basal ganglia lesions. Brain 112, 649.725 .

Lorenz, K. Z. (1981). The Foundations of Ethology. Springer-Verlag: New York.

Luxenberg, J. S., Swedo, S. E., Flament, M. F., Friedland, R. P., Rapaport, J. L. \& Rapaport, S. I. (1988). Neuroanatomical abnormalities in obsessive-compulsive disorder detected with quantitative X-ray computed tomography. American Journal of Psychiatry 145, 1089-1093.

MacLean, P. D. (1978). Effects of lesions of globus pallidus on species-typical display behaviour of squirrel monkeys. Brain Research 149, 175-196.

Murphy, M. R., MacLean, P. D. \& Hamilton, S. C. (1981). Speciestypical behavior of hamsters deprived from birth of the neocortex. Science 213, 459-461.

Osler, W. (1894). On Chorea and Choreiform Affections. Blakiston \& Son: Philadelphia.

Pauls, D. L., Towbin, K. E., Leckman, J. F., Zahner, G. E. P. \& Cohen, D. J. (1986). Gilles de la Tourette's syndrome and obsessive-compulsive disorder: evidence supporting a genetic relationship. Archives of General Psychiatry 43, 11801182.

Pazos, A., Cortes, R. \& Palacios, J.M. (1985). Quantitative autoradiographic mapping of serotonin receptors in the rat brain. II. Serotonin-2 receptors. Brain Research 346, 231249.

Pazos, A. \& Palacios, J. M. (1985). Quantitative autoradiographic mapping of serotonin receptors in the rat brain. I. Serotonin-1 receptors. Brain Research 346, $205-230$.

Schneider, J. S. (1984). Basal Ganglia role in behavior: importance of sensory gating and its relevance to psychiatry. Biological Psychiatry 19. 1693-1709.

Steinbusch, H. (1981). Distribution of serotonin-immunoreactivity in the central nervous system of the rat. Neuroscience 6, 557.618.

Stuart, A., Slater, J. M., Unwin, H. L. \& Crossman, A. R. (1986). A semiquantitative atlas of 5-hydroxytryptamine- 1 receptors in the primate brain. Neuroscience 18, 619-639.

Swedo, S. E., Rapoport, J. L., Cheslow, D. L., Leonard, H. L., Ayoub, E. M., Hosier, D. M. \& Wald, E. R. (1989a). High prevalence of obsessive compulsive symptoms in patients with Sydenham's chorea. American Journal of Psychiairy 146, 246 249.

Swedo, S., Rapoport, J. L., Leonard, H., Lenane, M. \& Cheslow, D. 
(1989h). Obsessive compulsive disorder in children and adolescents. I. Clinical phenomenology of 70 consecutive cases. Archives of General Psychiatry 46, 335-341.

Swedo, S., Leonard, H., Rapoport, J., Lenane, M., Goldberger, E., Cheslow, D. (1989c). A double-blind comparison of clomipramine and desmethlyimipramine in the treatment of trichotillomania. New England J. Medicine (in the press).

Tonkonogy, J. \& Barreira, P. (1989). Observe-compulsive disorder and caudate-frontal lesion. Neuropsychiarry, Neuropsychology and Behavioural Neurology' 2, 203-209. von Economo, C. (1931). Encephalitis Lethargica: Its Sequellae and Treatment. Oxford University Press: London.

Wise, S. \& Rapoport, J. L. (1989). Obsessive-compulsive disorder: is it basal ganglia dysfunction? In Obsessive-Compulsive Disorder in Children and Adolescents (ed. J. L. Rapoport), pp. 327346. American Psychiatric Press: Washington, DC.

Zohar, J., Mueller, E. A., Insel, T. R., Zohar-Kadoven, R. C. \& Murphy, D. L. (1987). Serotonergic responsivity in obsessive-compulsive disorder: comparison of patients and healthy controls. Archives of General Psychiatry 44, 946-951. 